\title{
Bolivarian republic of Venezuela experimental national university “Jesus Mary semprúm”
}

\begin{abstract}
In the present study it was Proposed to generate core purpose as theoretical constructs That allowed the inclusion of the popular knowledge as an alternative for the university social transformation from the National Experimental University of the South of the Lake in the municipality Colon, Zulia state; It was tried under a dialogical view to Recognize the need to Achieve the materials transformation of the current society and try to reduce through the categorical propositions That Could Arise the impact of a society Where individually the, the students, but especially the university professor To reconnect and to commit Themselves in the reconstruction of structures for the generation of knowledge lead to a better That standard of life; A study That was worked from the methodological point of view in an ethnographic approach, epistemologically it was Approached from the interpretative approach vivencialista and from the ontology in an idealistic approach transcendental; The context of study was framed in the Zulian region, Specifically in the population of Santa Barbara, Municipality Colón, key Informants Were selected following some criteria That allowed the veracity and reliability of the information, Whose collection techniques Were the in-depth interview and Non -participant observation, and data analysis Were processed through interpretive categories in order to Establish under a process of triangulation That reality and Cultural Visualized That Contributed to generate inclusion as an alternative constructs for university transformation.
\end{abstract}

Keywords: Popular knowledge, impact, inclusion, university transformation.
Volume 2 Issue $6-2018$

\author{
Yeslando J Gonzalez B \\ Department of Education, University of Pedagogical,Venezuela
}

Correspondence: Yeslando J Gonzalez B, Department of Education, University of Pedagogical, UPEL,Venezuela, Tel 0424 7644407,Venezuela, Email yeslandogonzalez778@hotmail.com

Received: October 24, 2018 | Published: December 20, 2018

\section{Introduction}

The confrontation of human beings according Mora ${ }^{1}$ with its practices and concrete or imaginary realities collective and individual requires certain levels of information, knowledge, and management of complex situations for current university academic communities so they have to re-evaluate the scientific production and technology of each culture, people and/or inhabitant in order to try to achieve true integration. Otherwise, the company could run the risk of enlarging the environmental, social and humanitarian crisis being experienced. Similarly, if society presents crisis, universities and education not escape it, the knowledge that comes from the working classes, could represent a way of observing and interpreting reality that will promote university education other paths; However, in the current economic context also needs access to formal knowledge and official use socially accepted to understand the various mechanisms of modern life and thus fight for a new way of fairer sociability, where indeed human life is valued. In the university educational aspect, popular wisdom according to Rodriguez, ${ }^{2}$ can be incorporated as an essential part of a process of inclusive education that would represent a way of seeing academic life as a sum of aggregates cultural values and accepted as reconstruction of historical memory of peoples, another way to approach and observe the community by universities and emerging alternative for university social-educational change.

In this sense, this research tries from a dialogic look deepening about popular knowledge and build bridges for academic openness on the part of universities, especially in the South Universidad del Lago "Jesus Maria Semprum" (UNESUR) institution set in South of lake Maracaibo, Zulia State that shares its basin with the states of Mérida, Táchira and Trujillo, where as its inhabitants have samples of rootlessness and detachment that somehow leave gaps in students' personality, culture and structural knowledge of idiosyncrasy Surlaguense denoted to use the language characteristic of zuliano.

On the other hand, it showed a marked failure to identify communities with regard to college index so that the development of constructs that allow internalizing the problem, analyze it and try to rebuild experiences with a view to reuniting people-university aims. It is to explain the theoretical-practical challenges that could transform the surrounding reality and the way human beings in South Lake achieve the interaction of knowledge even in times of crisis. For the author the following work represents a mode of expression and reconstruction in the university educational aspect of the socio-culturalacademic interrelationships of Surlaguense communities. However, they appear operational gap between teaching practice and use of knowledge of the community, revealing a phenomenon that has been researched for several qualitative approaches; ethnomethodological and ethnographic, the results could be a fundamental part for the development of a work that brings us to a particular interpretation and a more humane contextualization of popular knowledge, and of course, the communities of South Lake.

\section{Developing}

Addressing aspects of qualitative research the structure of work focused on moments due to participation in terms of time provided for non-participant observation and semi interviews structured and worked with general purposes rather than objectives considered to they are part of an overall structural system. Based on the ideas presented research was structured as follows and is presented in summary as follows: 
a) Chapter I: empirical moment: The phenomenon of study in which he tried to explain the concept of popular wisdom, the way they perceive for academia and for South Lake College. Also study purposes described, justification, relevance of the topic and the various contributions many theoretical, pedagogical and methodological.

b) Chapter II: Theorist moment: Those foundations that contain previous studies and related research and theories on which it is based, as essential to interpret and understand the feelings zuliano own knowledge base.

c) Chapter III: presented the methodological approach in which research was framed from a perspective of ethnography, based on a descriptive and field analysis from introspective experiential approach epistemological, ontological under an eminently idealistic approach.

d) Chapter IV: clinical moment was titrated by specialized surgery that was applied to the review of the data, emerging category. The structure that was given to the information gathered, deepening their respective interpretation and vision of the researcher.

e) Chapter V: It is in the dialogue content, review and reflection so the vertex point where the gift of Prometheus and presents the final reflections calld. In this regard the investigation provided systematize the steps followed to generate theoretical constructs that allow the inclusion of popular knowledge as an alternative for university social transformation from the National Experimental "Sur Del Lago" University in the Colon of Zulia State.

From an ontological, historical and epistemic reconstruction root, universities as a center of scientific knowledge originated in XVII century with Fernando VII and have remained to this day with the same insights about knowledge and knowing, obviating what his methodology to investigate, recognized as human and approach to knowledge has been unable to define: the knowledge of the people. Peña, ${ }^{3}$ emphasizes the possibility that the human being is recreated from its history, of what was, is and wants to be, denoting a collective consensus from the knowledge of the town where the main feature is common sense to rethink future generations. From this perspective the concept of education arises from popular wisdom, which emerge at a time when humanity, educational institutions, societies busily looking for a new order to re-integrate and re-articulate the world that for their acts against the natural balance, seems to want to exclude them. Popular knowledge represents a way of humanizing the university culture and try to avoid elitist representations that inhabit it. Therefore, the holistic, understood as a concept that encompasses all human dimensions, is presented as a necessity for a sector of the population concerned about the transpersonal psychology, ecological and philosophical implications of quantum physics. It is not fully comprehend the social imaginary of the peoples that underlies each of the members of the university community but to recognize its transformational power of the university network and recompose the human being that ultimately ends subdued by science.

The problem object of study of this research came from the social and educational context that the time, place and participants play a key role. For this reason, in the words of it is in the educational social context of all players participating in the historical, cultural, social, and psychological and other becoming. Which affect a greater or lesser extent in the relations established between groups and individuals, customs, ideas, shaping ideals and concepts, explanations about the world and man Nuñez. ${ }^{4}$ Qualitative its own dialectic, systemic nature and its phenomenological start investigations should be structured according to the perception of the object of study by the researcher from and epistemological elements, ontological, teleological methodology as the framework Martinez ${ }^{5}$ should for its purpose "expose what has been done so far to clarify the phenomenon under investigation." Therefore, it is necessary to give greater emphasis to the closest, the regional, the national and even the Latin, but it should never be forced to impose an interpretation. Hence the need to adopt in words. ${ }^{5}$ Phenomenological attitude and posture.

\section{Research purposes}

General purpose of the study: Generating theoretical constructs that allow the inclusion of popular knowledge, as an alternative to university social transformation from the National Experimental University South Lake in the Colon of Zulia State.

\section{Specific purposes}

a) Characterize the concept of teaching on popular knowledge of the Zulia region in the educational context of the National Experimental University South Lake.

b) Interpreted through the concept of intersubjectivity popular knowledge from the perspective of university social transformation.

c) Provide spaces for reflection, integration and contributions that allow the approach of knowledge of peoples with official knowledge as an alternative for university social transformation.

d) Contribute from reflection elements that contribute to favor the inclusion of popular knowledge framed in a process of social transformation university.

\section{First item:The ontological plane}

a) Palpable reality

b) Dynamic object

c) Conventional wisdom born of the relationship of people and their cultural, material and immaterial productions

d) It encompasses all human dimensions

e) Identity construction of knowledge of the people and their culture

\section{Second element: the teleological level}

Reference to the purpose or purposes of the study object, its final according to specific processes of society causes was made.

\section{Features}

a) Human communication where there is a consensus on an equal footing.

b) The approach of popular knowledge for university social transformation.

c) Relationship of people among themselves and with their productions.

d) Recognition of historical identity, accepting the past and taking the present from the socio-political actors that make up the phenomena studied.

The epistemological level: This plane is primarily supported by Martíne $z^{5}$ in reviewing the different theories and concepts known by fundamental researchers to present and describe the characteristics of the most important directions in history as the object of study, paradigm and concrete reality that envelops the study.

\section{Features}

a) Introspective experiential paradigm; subject-subject, democratic and communicative 
b) Qualitative approach, semi-structured and unstructured interviews

c) Prevalence of the practice and they comprise phenomena are discovered under natural conditions

d) Participation-interaction

e) Reality of human action

\section{The methodological level}

It was taken as a starting point the naturalistic paradigm as an epistemological alternative because according Guber ${ }^{6}$ social science actually accesses a pre interpreted by the subjects. Instead of maximizing external objectivity with respect to the field, naturalists proposed fusion researcher with the study subjects, making it one apprehends more than the logic of the social as do its members. Therefore, the researcher did not set out to explain a culture but to interpret or understand. Therefore the most suitable techniques are less intrusive in everyday studied: The non-participant observation and in-depth interview or undirected.

\section{Features}

a) Ethnographic method: groups of people are studied

b) Non-participant observation and structured interviews applied or not

c) Records audio and video tapes and others are taken

\section{Methodology}

Interpretive research is handled with a different type of logic as suggested by the quantitative research approaches. Therefore it was also different budgets used to demonstrate findings and can be accepted. Ethnographic research prefers to speak of an epistemological validity, validity of consensus or "face to face", that is, its credibility is seriously guaranteed because the text is properly explained, based on material indicators, adapted to a theory, consisting of the terms of their reflection. As to the quality criteria that the credibility of qualitative research $\mathrm{Guba}^{7}$ is based include the following; the truth value, applicability, consistency and neutrality. The truth value/ credibility: refers to credible data based on the explanatory power and consistency between the different views. Therefore, in terms of research done and the application of the instrument, the "in situ" recording, transcription and analysis of the data it holds. According to the observed reality, participant observation and open interview, was obtained as follows: The popular knowledge are considered a particular reflection of the social, economic and cultural reality of its actors. This is reflected in the categories emerged from the responses obtained in terms of identity and self-recognition. He comes to recognize and respect the knowledge born of the people because they need to accept their origins and their influence on the transformation of educational life of human beings. He builds knowledge in the construction process of historical awareness and recognition of the other. Note that this type of education has spaces for inclusion and interpretation of this knowledge, based on classical authors such as Vygotsky $^{8}$ with his thesis originated higher psychological processes in relational dynamics of the subject with its history, culture and life social because it rises and promotes the integral development valid even today. Change and transformation are linked, since the change is constructed, it refers to the individual from the environment and the transformation is constructed from the collective within an environment. Hence the phrases "our grandparents"; "... no interest to educational institutions"; "Our own essence"; "I attended a midwife" of respondents. a) Consistency /dependence refer to the possibility of replicating the study and obtain the same findings. When an ethnography is done we study and analyze social groups so laughable lie or invent, even more so when the community is watching, if you're lying or not. And what's investigating?

b) Neutrality/reliability refers to the independence of the results against motivations, personal interests or theoretical connections researcher. That is, guarantee and assurance that the results are not biased. Here we can say that has reduced data been some idioms and expressions out of context. However, it has been replicated and transcribed the recordings. As basic strategies triangulation was performed and the experience of respondents, teachers, administrative workers and students to be effective are confronted and possesses both internal validity and external. In short, we tried to knock on the door but inside and listen to us. Therefore and according to Guber". Ethnographies not only report the empirical object of research-a people, a culture, a society..." constitute the interpretation/description of what the researcher saw and heard. Problematised ethnography presents the author's interpretation about some aspect of the reality of human action.

\section{Results}

It is known in advance that a job of this nature brings consequences followers and critics; a counter; others in favor. The risk is accepted. As for the narrative of the work could be written in first person, but do not get up there because everyone has made a contribution and from the point of view of recognition satisfactory to say: Thank you. From this view it was considered that the beliefs of the people of South Lake often are based on religious aspects, production, culture, campesinada, its idiosyncrasy as zulianos superimposing the fact the origin of the term Zulia. It is interesting how the wisdom and idiosyncrasy toponímica what, even when working in UNESUR and origin is of Maracaibo, capital of Zulia state, characteristics that are inherent to zuliano South Lake as they prefer to call themselves Surlaguense recognized. I am South Lake! This feature does not uproot the native, although there is a semantic distance of speech and the fact that conviviality both the accent and the maracaibero colons. Aspect that could be debated in university classrooms, training professorships to avoid widening of relations. Another feature that resides in the aspect that the Surlaguense does not like to be compared with those from Maracaibo also addressed. It is mentioned in this work, but not being deepened field of Sociology. Regarding social values added which has to do with family values that the family has lost meaning and the current Venezuelan government, it seems not place them restrictions on how why their children admitted to a university and what, becoming an "anti-value" of use. According to Barbero 9 mentions that at least in Latin America, contrary to the prophecies of the implosion of the social, the masses still contain the double sense of control but also to have in the institutions, the people, the plot thickens of miscegenation and strains of urban life. According to the researcher could become a scale of antivalores in a historic emergency survival but could dematerialize communities as culture and turn them into processes of cultural and social degradation University of South Lake and adjacent universities could control if their PNF access within their curriculum redesign, implementation and fomentation of culture and preparation of individual personality. For that we must be present, share, live and live together in South Lake Finally, consider how loss of values that the university educational institutions, especially South Lake College does not collaborate many times stregthening philosophical knowledge for example: the culture 
of study and research of the history of the municipalities, traditions, culture because this is an institution whose primary function is agricultural, livestock or technological production, was conceived as a model of productive university open

\section{Conclusion}

\section{The gift of Prometheus}

Greek mythology for one of the oldest and most common myths of their philosophical tradition is the stealing fire from the gods by a semi-god or a hero. Your name; Prometheus, who by stealing fire from Zeus and gave it to the men allowed them to develop the arts and progress. King of Olympus could not leave without such punishment challenge and ordered Hephaestus to manufacture a woman out of clay and founds' life. All goddesses lent their thanks and appeared the most beautiful creature ever created: Pandora and sent it as a gift (false bártulo) for the defense of men. ${ }^{10}$

Time to make the most feverish history have added him to the work and dedication did keep Prometheus outside the shelter of his beloved Pandora. Zeus sent a new gift in a small box where were all the misfortunes that awaited men (he did not forget the punishment), upon receiving the gift Pandora was curious and opened letting out all the evils and miseries of men ( hunger, pain, envy, hatred ...). Returning Prometheus and see the open box tried to close it. He caught only hope. And from there only men have as sure hope. This work grew out of hope; go looking for a real transformation for South Lake University (UNESUR). This allowed work with communities, farmers, community councils and Afro-descendants from where he grew up and marrow of this research was formed: The gift of Prometheus. Who alone is expected to open it, do it with academic interest and contribution, work is not lifted. Doubt appears, it was one or there were two gifts. At the present time necessarily you need to build bridges between reality and purely academic in regard to the role of universities and institutions. Academicismo still avoiding pedagogies of Humanities because they were the Greeks and the Orientals who gave the humanist character of the interrelation and social tradition. Recognition of the social and the collective is in man by his individuality and the need to come together. Group and individual to say Loruso ${ }^{11}$ knowledge was forged learned to control fire, the higher arts, the wheel was invented, he learned to imitate animals in flight, sound and water, but he was forgotten tradition. He had to invent to try to achieve the organization and order. He was allowed to escape the human essence. Animal gods Harari ${ }^{12}$ In this regard, university education should enable and strengthen educational links exceeding the hierarchy of academic knowledge that are not the most suitable for solving immediate problems with which the worker is at the time of production and harvest food.

\section{Acknowledgments}

None.

\section{Conflicts of interest}

Author declares that there is none of the conflicts.

\section{References}

1. Mora, D. Dialogo and dialectical transfer of knowledge/skills. Magazine. Educational integrates. Peace: Bolivia; 2013.

2. Rodriguez J. Approach to a model of social participation to strengthen the quality of life from the context of Venezuelan education. doctoral thesis. Spain: University of Cordoba; 2014.

3. Peña A. Popular knowledge as an engine of citizens and institutions transformer change. Electronic item. 2012.

4. Nunez J. The peasant knowledge: implications for rural education. Venezuela: (UPEL-IPRGR); 2004.

5. Martinez M. Ethnographic research method. 2005.

6. Guber R. Ethnography: Method, field, and reflexivity. Ethnology Social Anthropology Research Tít. II. Bogotá. 2001.

7. Guba E. criteria naturopathic credibility investigation. In: Gimeno Sacristan, Gomes Pérez, editor. Education, its theory and practice. UK: Edic. AKAL; 1989. p. 148-165.

8. Vigotsky LS. The development of psychological processes. Mexico: Grijalbo higher; 1976.

9. Barbero JM. From media to mediations, Communication, culture and hegemony. GG media. 2nd ed. Spain: Editorial Gili, SA; 1991. 288 p.

10. Julian N. Encyclopedia of Myths. Santa Fe. Bogotá: Robin Book; 1997.

11. Loruso A, Lydia R. Higher Education and the recognition of socially productive knowledge of the popular sectors. Magazine: Voices in Phoenix. Buenos Aires: UBA; 2014. p. 79-84.

12. Harari YN. Animal gods. A Brief History of Humanity. Spain: University press; 2014. 